\title{
Body light points to health
}

Tokyo

THE Research and Development Council (RDC) of the Japanese Science and Technology Agency has sufficient confidence in Professor Humio Inaba of Tohoku University to invest about Y15,000 ( $£ 70$ million) in his research. For Inaba believes that the light people emit may reflect the state of their health.

Inaba's team has found that the blood of patients suffering from diseases such as cancer, diabetes and jaundice gives off much more light as that of healthy people. Smokers' blood "glows" twice as brightly as that of non-smokers, but returns to normal after a day of not smoking.

Although the mechanism of photoemission in each of these cases has still to be determined, peroxidation of lipids through the generation of activated oxygen and free radicals is believed to be involved. Peroxidal lipid reactions are suspected agents in diabetes, liver and lung diseases, arteriosclerosis, ageing and cancer. Inaba believes biophotons will eventually be used for diagnostic and clinical purposes.

The biophoton project is one of the latest additions to Japan's ERATO programme, which was set up in 1981 in a radical attempt to break free from Japan's conservative research system.

ERATO projects run for five years and, with the sole exception of the project leader, the 20 or so participants are all young researchers (under 35) drawn equally from universities, government research institutes and industry. Two or three foreigners are usually included in the team and

\section{SERC annual report}

THE UK Science and Engineering Research Council (SERC) has asked the government, through the Advisory Board for the Research Councils, for an extra £20 million to make up the shortfall in its budget for 1987-88 due to unfavourable fluctuations of the pound against European currencies. The disclosure was made last week on the publication of SERC's annual report.

Professor E. W. J. Mitchell, chairman of the council, in the introduction to the report, claimed: "Overall the council's task remains the achievement of a sensible balance between curiosity-driven basic research, the seed corn of the future, and the strategic work where application might be anticipated in the medium term. This task is made more difficult within a severely contrained budget, further exacerbated by the wayward behaviour of the exchange rates which in 1985-86 were invariably against us."

Bill Johnstone the research is carried out in independent laboratories uncontaminated by the usual environment of Japan's academic and government research laboratories. Once the theme of the project is chosen, the teams are left to find their own path, sometimes with bizarre consequences.

Inaba, who is attached to Tohoku University's Research Institute of Electrical Communication, became involved in maser research in the late 1950 s, during an unsuccessful bid to get a large radiotelescope built in the Tohoku area north of Tokyo. In the $1960 \mathrm{~s}$, he turned to the development of high-sensitivity detectors for lasers, and by the end of the decade had devised a laser system for the detection of air pollution using highly sensitive photomultipliers to pick up the scattered light (Nature 224, 57; 1969).

Using Inaba's equipment, biochemists trying to detect the low levels of light ex- pected to be given off during biochemical reactions involving peroxidation were able to detect ultraweak light emissions (of the order of tens of photons per second) from tumours and regenerating livers in mice and rats. But dark noise prevented determination of the spectrum of the emitted light.

Inaba's team, with support from RDC, went on to develop a luminescence analyser in collaboration with Tohoku Electronic Industrial Co. Ltd that can detect less than one photon per second and can handle samples up to the size of a rabbit.

The project will aim at improving this technology to allow measurement of weak biophoton emissions and to bring spatial resolution ot the sub-micron level.

The technology has already found applications in the salad oil, rubber, paint and powdered milk industries, where the degree of oxidative deterioration of the product can be checked in a few minutes by monitoring ultraweak chemiluminescence. But medical applications seem to hold most promise.

\section{Nuclear safety \\ NRC investigates Seabrook}

\section{Boston}

THE alleged misuse of drugs and alcohol by construction workers may have compromised the safety of the Seabrook Nuclear Power Plant in Seabrook, New Hampshire, which is due to begin lowpower testing at the end of this year. The Nuclear Regulatory Commission (NRC) is now investigating these allegations.

The outcome of the inquiry is likely to affect both the debate about mandatory drug testing and that about existing controls on the safety of nuclear power plants. Drug tests are opposed by those who consider them an infringement of personal liberty.

Several groups, including the energy conservation and power subcommittee of the House of Representatives headed by Congressman Edward J. Markey (Democrat, Massachusetts), have gathered allegations from police, hospital personnel and court employees as well as from the construction workers themselves. The alleged abuses are said to have transformed the town during the ten years of construction.

Former plant workers called Seabrook “a drug addicts' haven". Police have reported finding steel workers "drunk, coming and going" and, according to Dr Gary Lamphere of Exeter Hospital, "it was unusual enough in the early 1980 s to see a Seabrook patient without alcohol on his breath to remark on it".

The issue is not whether workers constructing nonvital areas of the nuclear power plant were drunk or high on drugs, says Thomas Elsasser of NRC's Pennsyl- vania office, but whether "systems essential to safety" have been affected. NRC will judge Seabrook's safety by inspecting documents, examining systems on a sampling basis and monitoring containment and fuel-load tests.

So far, Seabrook has passed all tests:

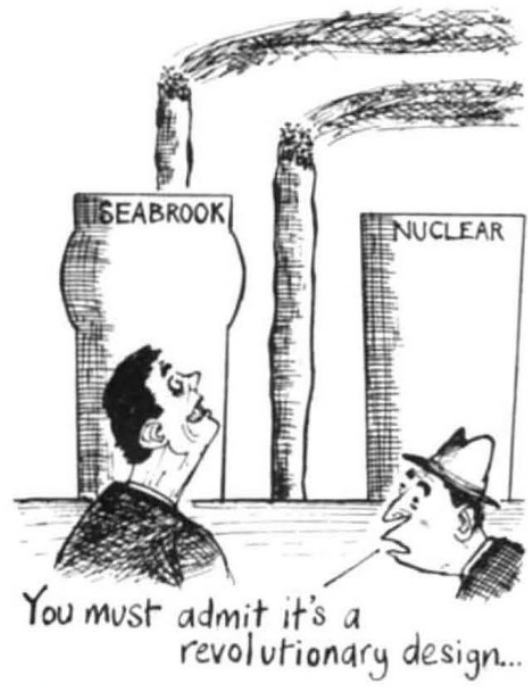

21,000 hours of inspection by NRC, almost twice that for any other plant in the region, have uncovered no structural reason to believe the plant is unsafe.

But testing after construction is considered unsatisfactory because some parts of the plant are no longer accessible for inspection. NRC may face other obstacles: $t i$ is alleged that some quality control inspections were not completed properly nor documented correctly.

Elizabeth Collins 